\title{
Papers
}

\section{Interventions used in disease management programmes for patients with chronic illness-which ones work? Meta-analysis of published reports}

\author{
Scott R Weingarten, James M Henning, Enkhe Badamgarav, Kevin Knight, Vic Hasselblad,
} Anacleto Gano Jr, Joshua J Ofman

\begin{abstract}
Objective To systematically evaluate the published evidence regarding the characteristics and effectiveness of disease management programmes. Design Meta-analysis.

Data sources Computerised databases for English language articles during 1987-2001.

Study selection 102 articles evaluating 118 disease management programmes.

Main outcome measures Pooled effect sizes calculated with a random effects model.

Results Patient education was the most commonly used intervention (92/118 programmes), followed by education of healthcare providers $(47 / 118)$ and provider feedback (32/118). Most programmes $(70 / 118)$ used more than one intervention. Provider education, feedback, and reminders were associated with significant improvements in provider adherence to guidelines (effect sizes (95\% confidence intervals) 0.44 (0.19 to 0.68$), 0.61$ (0.28 to 0.93 ), and 0.52 (0.35 to 0.69 ) respectively) and with significant improvements in patient disease control (effect sizes 0.35 (0.19 to 0.51$), 0.17$ (0.10 to 0.25$)$, and 0.22 (0.1 to 0.37 ) respectively). Patient education, reminders, and financial incentives were all associated with improvements in patient disease control (effect sizes 0.24 ( 0.07 to 0.40$), 0.27$ (0.17 to 0.36$)$, and 0.40 (0.26 to 0.54 ) respectively).

Conclusions All studied interventions were associated with improvements in provider adherence to practice guidelines and disease control. The type and number of interventions varied greatly, and future studies should directly compare different types of intervention to find the most effective.
\end{abstract}

\section{Introduction}

Chronic diseases account for billions of dollars in annual medical expenditures. In the United States asthma, depression, and diabetes are estimated to account for $\$ 5.1 \mathrm{bn}$ (£3.4bn, €5.2bn), \$12.4bn, and $\$ 44$ bn respectively, in annual direct medical costs. ${ }^{1-3}$ Loss of work time and decreased worker productivity contribute to indirect costs. Unsurprisingly, therefore, there has been much interest in systematically improv- ing the quality and reducing the cost of caring for patients with chronic illness.

Disease management programmes have proliferated recently as a means of improving the quality and efficiency of care for patients with chronic illness. Ellrodt et al defined disease management as a multidisciplinary approach to care for chronic diseases that coordinates comprehensive care along the disease continuum across healthcare delivery systems. ${ }^{4}$ Epstein defined disease management as a population based approach to health care that identifies patients at risk, intervenes with specific programmes of care, and measures outcomes. ${ }^{5}$ These programmes may represent an important improvement in the quality and value of health care for patients with chronic illnesses. However, disease management programmes can be costly to develop, implement, and evaluate. According to the Disease Management Association of America, an estimated \$1bn was spent in 1999 to develop and implement disease management programmes. ${ }^{6}$ Despite the investment, evidence supporting the effectiveness of disease management is sparse. A limited number of published trials have documented the effectiveness of disease management in specific situations, but uncertainty remains about its overall value. Understanding which interventions are most effective could guide the development of disease management programmes.

Several qualitative reviews have described the effects of interventions such as educational programmes, giving feedback to healthcare providers, and patient financial incentives to promote adherence to practice guidelines. Oxman et al reviewed 102 trials and concluded that a wide range of interventions may improve practice but that there are no "magic bullets." Davis et al showed that educational interventions improved physician performance and possibly patient outcomes. ${ }^{8}$ Mugford found provider feedback effective when part of an overall implementation strategy. ${ }^{9}$ There have also been some qualitative descriptions of interventions to implement practice guidelines. ${ }^{10-12}$ Although these reviews covered a wide range of interventions, no review focused on interventions used in disease management programmes for patients with chronic illness. Additionally, there have been only lim-
Zynx Health, 9100 Wilshire Boulevard $665 \mathrm{E}$, Beverly Hills, CA 90212, USA

Scott R Weingarten president

Enkhe Badamgarav clinical project leader Kevin Knight research manager Anacleto Gano Jr research associate Joshua J Ofman senior vice president research

TAP

Pharmaceutical Products, Lake Forest, IL, USA James M Henning associate director

Duke Clinical Research Institute, Duke University, Durham, NC, USA

Vic Hasselblad

associate research professor

Correspondence to: S Weingarten sweingarten@ cerner.com

bmj.com 2002;325:925

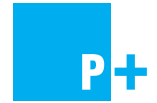

Further details of this review appear on bmj.com and details of the studies reviewed appear on the authors' website 
ited evaluations of the quantitative effects of specific types of interventions to complement qualitative and descriptive information. This study reviews the types of interventions used in published trials of disease management programmes and provides quantitative and qualitative evaluation of the evidence regarding the effectiveness of different types of intervention.

\section{Methods}

\section{Literature review}

We performed a systematic review of the medical literature to identify studies evaluating the effectiveness of disease management programmes in improving care or reducing costs for patients with common chronic conditions. In collaboration with a librarian experienced in searching computerised bibliographic databases, we conducted a search of the Medline, HealthStar, and Cochrane databases for English language articles published between January 1987 and June 2001. The search used the following medical subject heading $(\mathrm{MeSH})$ terms: patient care team, patient care planning, primary nursing care, case management, critical pathways, primary health care, continuity of patient care, guidelines, practice guidelines, disease management, comprehensive health care, ambulatory care, and the title words "disease state management" and "disease management" (see appendix 1 on bmj.com). Hand searches of bibliographies from relevant articles and reviews and consultations with experts in the subject yielded further references.

Our working definition of disease management was "an intervention designed to manage or prevent a chronic condition using a systematic approach to care and potentially employing multiple treatment modalities." We defined a guideline or systematic approach to care as systematically developed statements to assist practitioner and patient decisions about appropriate health care for a specific clinical circumstance. ${ }^{43}$ To determine whether a programme incorporated a systematic approach to care, we searched for keywords such as guidelines, protocols, algorithms, quality improvement programmes, care plans, and standardised patient and provider education. We excluded programmes aimed exclusively at evaluations of single treatment methods (such as psychotherapy or specific drugs) and drug compliance programmes. We rejected articles if they included only paediatric cases or if they were reviews, case reports, editorials, letters, or meeting abstracts. We also rejected articles if they did not use acceptable experimental or quasi-experimental study designs as defined by the Cochrane Effective Practice and Organisation of Care (EPOC) Group's criteria for acceptable study designs, ${ }^{14}$ or if they did not report sufficient information to allow for estimation of at least one relevant measure of programme effect and its variance. Failure to meet this criterion could be due to inadequate reporting of results or to lack of an appropriate comparison group.

Based on these explicit inclusion and exclusion criteria for titles, abstracts, and articles, two reviewers trained in health services research and the principles of critical appraisal independently reviewed random samples of titles, abstracts, and reviews. Inter-rater agreement was assessed using the $\kappa$ statistic, and reviews were split between reviewers if a sufficient level of agreement was achieved $(\kappa>0.7)$. Results from accepted articles reporting results for disease management programmes were used to address study objectives.

\section{Classification of interventions}

Intervention components were classified as follows:

- Provider education-Materials or instruction given to healthcare providers regarding appropriate care for patients with the condition targeted by the programme - Provider feedback-Information given to healthcare providers regarding the specific care or results of care received or experienced by their patients

- Provider reminders-Prompts given to providers to perform specific patient care tasks

- Patient education-Materials and instructions issued to patients providing information on their condition and how it could be managed

- Patient reminders-Prompts given to patients to perform specific tasks related to care for their condition

- Patient financial incentives-Payments (direct monetary payments, discounts, or services) made to patients for achieving specific treatment related goals.

We also searched for programmes using provider financial incentives but found no such interventions. The proportions of interventions using each of the different interventions were described, as were the proportions with one, two, three, or four components (no intervention included more than four components).

Classification of process measures or outcomes Our analyses focused on measures of provider adherence to guidelines as key processes of care and on measures of disease control as key outcomes of care.

\section{Extraction of data}

Using a standardised abstraction form, we collected data describing interventions, components used, study design, population characteristics, sample size, intervention strategies, and measures of programme effects on processes and outcomes of care from unmasked articles that met our inclusion criteria. For each disease and condition, we had a defined method for selecting each disease specific process or outcome indicator as a measure of disease control (see appendix 2 on bmj.com). We treated multiple reports of results from the same study as a single programme evaluation. Reports with multiple intervention arms contributed one observation for each. When separate results were reported for mutually exclusive subgroups, each subgroup contributed an observation, and the overall results were not included.

When appropriate, we used changes over baseline values rather than follow up values in our analyses. Variances for changes over baseline were often not reported, in which case we assumed that the variance for the change was equal to the average of the variances of the baseline and follow up distributions if both were given. If the baseline variance was not provided, we assumed that the variance for the change was equal to the variance of the follow up distribution.

\section{Meta-analysis}

We calculated effect sizes-defined as a difference between the means of the treatment and control arms divided by the pooled estimate of the standard 
deviation (continuous variables) or the log odds ratio multiplied by a constant variance term (binary outcomes $)^{15}$-for each study outcome to allow pooling of similar outcomes. ${ }^{16-19}$ We constructed effect sizes so that positive numbers denoted treatment benefit. The method of interpreting the clinical importance of different effect sizes has been reported previously. ${ }^{20}$

We used the more conservative random effects, empirical bayesian method of Hedges and Olkin to pool the estimated effects. ${ }^{18}$ We pooled results for interventions incorporating each intervention component for disease control measures. ${ }^{21}$ For measures of provider adherence to care, we pooled results for interventions containing each intervention component except patient education (we concluded a priori that patient education would have minimal effect on provider adherence to guidelines). We also pooled results for each of these measures for interventions containing one, two, three, and four intervention components. When more than one process or outcome result within a category was reported for the same group of subjects, we used the one associated with the smallest effect size. Results are reported as pooled effect sizes with $95 \%$ confidence intervals.

\section{Results}

\section{Literature review}

Our initial search strategy identified 16917 references published between January 1987 and June 2001 (figure). We accepted 2963 titles for further screening, and 581 abstracts met our explicit inclusion criteria. Of these abstracts, $493(85 \%)$ failed to meet our inclusion criteria when the articles were reviewed. Bibliographic hand searches and expert consultation yielded an extra 51 articles for review, of which 14 were accepted. In total 102 studies met our criteria for inclusion. Multiple reports of the same intervention reduced the count of studies by 17 .

The 102 accepted studies evaluated 118 discrete intervention programmes and reported 352 estimates of programme effect. In 67 (19\%) cases, these estimates were selected from two or more reported results within a single subdomain based on rules delineated in the

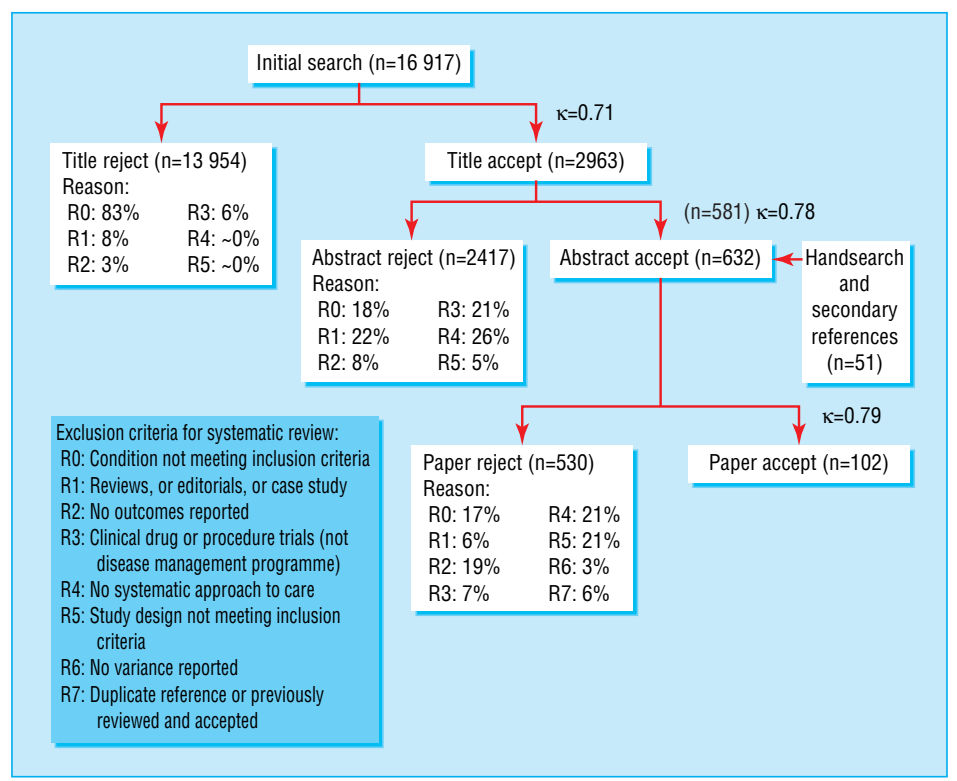

Selection process for including studies in systematic review

methods section. Selected programmes were heterogeneous with regard to the types of intervention they used (table 1). Of the 118 programmes, 92 used patient education, 47 used provider education, 32 used provider feedback, 28 used patient reminders, 19 used provider reminders, and only six used financial incentives for patients.

Patient education was an integral part of most programmes studied ( $9 / 9$ for congestive heart failure, $3 / 3$ for chronic pain, $6 / 7$ for back pain, $6 / 7$ for chronic obstructive pulmonary disease, and 21/26 for diabetes). However, provider education was widely used for only a few conditions-depression (17/25), diabetes $(9 / 26)$, hypertension (5/8), and hyperlipidaemia $(4 / 7)$. The six programmes that used financial incentives for patients were for asthma, depression, hyperlipidaemia, and hypertension. Patient reminders were often used in programmes for patients with congestive heart failure (4/9), coronary artery disease $(3 / 6)$, and diabetes $(9 / 26)$.

Table 1 Types of interventions including specific components

\begin{tabular}{|c|c|c|c|c|c|c|}
\hline \multirow{2}{*}{$\begin{array}{l}\text { Condition (No of } \\
\text { programmes) }\end{array}$} & \multicolumn{3}{|c|}{ Provider interventions } & \multicolumn{3}{|c|}{ Patient interventions } \\
\hline & Education & Feedback & Reminders & Education & Reminders & Financial \\
\hline Asthma $(n=10)$ & $1^{w 1}$ & $1^{w 2}$ & $1^{\mathrm{w} 2}$ & 9 w1 w3 w4* w5-w9 & $3^{\text {w2 w3 w8 }}$ & $2^{w 4^{*}}$ \\
\hline Back pain $(\mathrm{n}=7)$ & 0 & $2^{\text {w10 w11 }}$ & 0 & 6 w10 w12 w13* w14 w15 & 1 w10 & 0 \\
\hline Chronic pain $(n=3)$ & $1^{\text {w22 }}$ & 0 & 0 & $3^{w 22}$ w23* & 0 & 0 \\
\hline Congestive heart failure $(n=9)$ & $1^{\text {w24 }}$ & $3^{\text {w25-w27 }}$ & 0 & 9 w24-w32 & $4^{\text {w28-w31 }}$ & 0 \\
\hline $\begin{array}{l}\text { Chronic obstructive pulmonary } \\
\text { disease }(\mathrm{n}=7)\end{array}$ & $3^{\text {w33* w34 }}$ & 0 & 0 & $6^{\text {w33 } 3^{*} w 35-w 38}$ & $1^{\text {w35 }}$ & 0 \\
\hline \multirow[t]{2}{*}{ Depression $(n=25)$} & $17^{\text {w39-w44 w45* w46-w49 w50* }}$ & 18 w43 w44 w46-w49 w50* w51* & $8^{\text {w45* w49 w50* w51* w54 }}$ & 20 w41 w42 w44 w45* w46-w49 w50* w51* & 3 w56 w57* & 1 w52 \\
\hline & w51*w52 & w52 w53* w54-w56 w57* & & w52 w53 w55 w56 w57^ w58 & & \\
\hline \multirow[t]{2}{*}{ Diabetes $(n=26)$} & 9 w59 w60* w61 w62 w63* w64 w65 & $3^{\mathrm{w} 65-\mathrm{w} 67}$ & $5^{w 63^{*} w 65 \text { w68 w69 }}$ & $21^{w 60^{*}}$ w61 w62 w63* w64 w67-w70 w71 & 9 w64 w65 w67-w69 w77-w80 & 0 \\
\hline & & & & w72-w79 & & \\
\hline End stage renal disease $(n=1)$ & 0 & 1 w81 & $1^{\text {w81 }}$ & $1^{\text {w81 }}$ & 0 & 0 \\
\hline Hyperlipidaemia $(\mathrm{n}=7)$ & $4^{\text {w82 w83 w84* }}$ & $2^{\text {w85 w86 }}$ & $2^{\text {w82 w83 }}$ & 4 w82 w85-w87 & 1 w87 & 1 w85 \\
\hline Hypertension $(\mathrm{n}=8)$ & $5^{\text {w34 w88 w89 w90* }}$ & 1 w89 & $1^{w 91}$ & 2 w88 w92 & 0 & $2^{\text {w92 w93 }}$ \\
\hline $\begin{array}{l}\text { Rheumatoid arthritis and } \\
\text { osteoarthritis }(n=9)\end{array}$ & $3^{\text {w94-w96 }}$ & 0 & 0 & $7^{\text {w99 w97-w102 }}$ & 3 w94 w97 w98 & 0 \\
\hline All conditions $(\mathrm{n}=118)$ & 47 & 32 & 19 & 92 & 28 & 6 \\
\hline
\end{tabular}


Table 2 Number of different interventions used in disease management programmes for chronic diseases

\begin{tabular}{|c|c|c|c|c|}
\hline \multirow[b]{2}{*}{ Condition (No of programmes) } & \multicolumn{4}{|c|}{ No of interventions in programme* } \\
\hline & 1 & 2 & 3 & 4 \\
\hline Asthma $(\mathrm{n}=10)$ & 4 & 5 & 1 & 0 \\
\hline Back pain $(n=7)$ & 6 & 0 & 1 & 0 \\
\hline Coronary artery disease $(n=6)$ & 2 & 2 & 2 & 0 \\
\hline Chronic pain $(n=3)$ & 2 & 1 & 0 & 0 \\
\hline Congestive heart failure $(n=9)$ & 1 & 8 & 0 & 0 \\
\hline Chronic obstructive pulmonary disease $(n=7)$ & 4 & 3 & 0 & 0 \\
\hline Depression $(n=25)$ & 4 & 6 & 9 & 6 \\
\hline Diabetes $(n=26)$ & 12 & 8 & 5 & 1 \\
\hline End stage renal disease $(\mathrm{n}=1)$ & 0 & 0 & 1 & 0 \\
\hline Hyperlipidaemia $(\mathrm{n}=7)$ & 2 & 3 & 2 & 0 \\
\hline Hypertension $(\mathrm{n}=8)$ & 5 & 3 & 0 & 0 \\
\hline Rheumatoid arthritis and osteoarthritis $(n=9)$ & 6 & 2 & 1 & 0 \\
\hline All conditions $(n=118)$ & 48 & 41 & 22 & 7 \\
\hline
\end{tabular}

${ }^{*}$ No programme had more than 4 interventions.

The number of different interventions included in each disease management programme varied, with 48 programmes using a single intervention, 41 using two, 22 using three, and seven using four interventions (table 2).

\section{Impact of programmes with provider interventions}

Disease control

We identified 32 programmes addressing six conditions that included provider education and evaluated disease control (table 3). ${ }^{22-42} 515456577685$ Twelve of these (38\%) produced significant improvements in disease control. $^{24} 303133$ 34 36-42 Disease management for depression and diabetes had the highest percentage of programmes that produced significant benefits $(40 \%$ $(6 / 15)$ and $25 \%(2 / 8)$, respectively). Overall, programmes that included provider education showed a modest but significant improvement in disease control (effect size 0.35 (95\% confidence interval 0.19 to 0.51$)$ ).

Twenty three programmes addressing asthma depression, diabetes, renal disease, hyperlipidaemia, and hypertension included provider feedback and evaluated disease control (table 3). ${ }^{23} 242729$ 31-33 42-52 5484 Of these, nine (39\%) showed significant improvements in disease control (eight of which were depression programmes). ${ }^{24} 31334244-4784$ Overall, programmes with provider feedback produced a small but significant improvement in disease control (effect size 0.17 ( 0.1 to $0.25))$.

Table 3 Effects of disease management programmes with interventions directed at healthcare providers on disease control

\begin{tabular}{|c|c|c|c|c|c|c|}
\hline \multirow[b]{2}{*}{ Condition } & \multicolumn{2}{|c|}{ Programmes with provider education } & \multicolumn{2}{|c|}{ Programmes with provider feedback } & \multicolumn{2}{|c|}{ Programmes with provider reminders } \\
\hline & $\begin{array}{l}\text { No of effective } \\
\text { programmes* }\end{array}$ & $\begin{array}{c}\text { Pooled effect size } \\
(95 \% \mathrm{CI})\end{array}$ & $\begin{array}{l}\text { No of effective } \\
\text { programmes* }\end{array}$ & $\begin{array}{c}\text { Pooled effect size } \\
(95 \% \mathrm{Cl})\end{array}$ & $\begin{array}{l}\text { No of effective } \\
\text { programmes* }\end{array}$ & $\begin{array}{c}\text { Pooled effect size } \\
(95 \% \mathrm{Cl})\end{array}$ \\
\hline Asthma & & & $0 / 1$ & 0.03 (-0.1 to 0.19$)$ & $0 / 1$ & $0.03(-0.1$ to 0.19$)$ \\
\hline \multicolumn{7}{|l|}{ Back pain } \\
\hline Coronary artery disease & $0 / 1$ & $0.39(-0.03$ to 0.81$)$ & & & & \\
\hline \multicolumn{7}{|l|}{ Chronic pain } \\
\hline \multicolumn{7}{|l|}{ Congestive heart failure } \\
\hline \multicolumn{7}{|l|}{$\begin{array}{l}\text { Chronic obstructive } \\
\text { pulmonary disease }\end{array}$} \\
\hline Depression & $6 / 15$ & 0.32 (0.11 to 0.52$)$ & $8 / 15$ & $0.22(0.13$ to 0.31$)$ & $2 / 5$ & $0.29(-0.01$ to 0.61$)$ \\
\hline Diabetes & $2 / 8$ & $0.21(0.1$ to 0.34$)$ & $0 / 3$ & $0.19(0.02$ to 0.37$)$ & $2 / 4$ & $0.28(0.12$ to 0.44$)$ \\
\hline End stage renal disease & & & $0 / 1$ & $-0.25(-0.4$ to -0.06$)$ & $0 / 1$ & $-0.25(-0.4$ to -0.06$)$ \\
\hline Hyperlipidaemia & $1 / 2$ & $0.24(0.04$ to 0.43$)$ & $1 / 2$ & $0.25(0.06$ to 0.43$)$ & $1 / 2$ & $0.24(0.04$ to 0.43$)$ \\
\hline Hypertension & $2 / 5$ & $0.67(-0.15$ to 1.5$)$ & $0 / 1$ & $0.08(-0.01$ to 0.17$)$ & $1 / 1$ & $0.52(0.1$ to 0.93$)$ \\
\hline $\begin{array}{l}\text { Rheumatoid arthritis } \\
\text { and osteoarthritis }\end{array}$ & $1 / 1$ & 0.78 (0.06 to 1.5$)$ & & & & \\
\hline All conditions $(n=73)$ & $12 / 32$ & 0.35 (0.19 to 0.51$)$ & 9/23 & 0.17 (0.1 to 0.25$)$ & $6 / 14$ & $0.22(0.1$ to 0.37$)$ \\
\hline
\end{tabular}

${ }^{*}$ No of assessments showing significant treatment benefit $(\alpha=0.05) /$ total No of assessments.

Table 4 Effects of disease management programmes with interventions directed at healthcare providers on provider adherence to guidelines

\begin{tabular}{|c|c|c|c|c|c|c|}
\hline \multirow[b]{2}{*}{ Condition } & \multicolumn{2}{|c|}{ Programmes with provider education } & \multicolumn{2}{|c|}{ Programmes with provider feedback } & \multicolumn{2}{|c|}{ Programmes with provider reminders } \\
\hline & $\begin{array}{l}\text { No of effective } \\
\text { programmes* }\end{array}$ & $\begin{array}{l}\text { Pooled effect size } \\
(95 \% \mathrm{Cl})\end{array}$ & $\begin{array}{l}\text { No of effective } \\
\text { programmes* }\end{array}$ & $\begin{array}{l}\text { Pooled effect size } \\
(95 \% \mathrm{Cl})\end{array}$ & $\begin{array}{l}\text { No of effective } \\
\text { programmes* }\end{array}$ & $\begin{array}{l}\text { Pooled effect size } \\
(95 \% \mathrm{CI})\end{array}$ \\
\hline \multicolumn{7}{|l|}{ Asthma } \\
\hline \multicolumn{7}{|l|}{ Back pain } \\
\hline Coronary artery disease & $1 / 1$ & 2.64 (2.49 to 2.79$)$ & $1 / 1$ & 2.64 (2.49 to 2.79$)$ & & \\
\hline \multicolumn{7}{|l|}{ Chronic pain } \\
\hline Congestive heart failure & & & $0 / 1$ & $0.29(-0.14$ to 0.72$)$ & & \\
\hline \multicolumn{7}{|l|}{$\begin{array}{l}\text { Chronic obstructive } \\
\text { pulmonary disease }\end{array}$} \\
\hline Depression & $9 / 14$ & 0.51 (0.31 to 0.71$)$ & $8 / 12$ & 0.53 (0.32 to 0.75$)$ & $5 / 8$ & 0.55 (0.36 to 0.74$)$ \\
\hline Diabetes & $1 / 3$ & $0.23(0.1$ to 0.35$)$ & $0 / 2$ & $0.08(-0.17$ to 0.34$)$ & $1 / 2$ & 0.36 (0.02 to 0.7$)$ \\
\hline \multicolumn{7}{|l|}{ End stage renal disease } \\
\hline Hyperlipidaemia & $1 / 2$ & $0.05(-0.13$ to 0.23$)$ & & & & \\
\hline Hypertension & $0 / 4$ & $0(-0.13$ to 0.13$)$ & & & & \\
\hline \multicolumn{7}{|l|}{$\begin{array}{l}\text { Rheumatoid arthritis and } \\
\text { osteoarthritis }\end{array}$} \\
\hline All conditions & $12 / 24$ & $0.44(0.19$ to 0.68$)$ & $9 / 16$ & $0.61(0.28$ to 0.93$)$ & $6 / 10$ & 0.52 (0.35 to 0.69$)$ \\
\hline
\end{tabular}

${ }^{*}$ No of assessments showing significant treatment benefit $(\alpha=0.05) /$ total No of assessments. 
Fourteen programmes incorporating provider reminders evaluated disease control (table 3). $.^{29-31} 3639435053-5585$ Of these, six (43\%) significantly improved disease control. ${ }^{30} 3136395355$ Programmes with provider reminders were effective for patients with diabetes and hyperlipidaemia. Overall, the programmes made a small but significant improvement in disease control (effect size 0.22 (0.1 to 0.37 )).

\section{Provider adherence to guidelines}

Twenty four programmes that included provider education assessed measures of provider adherence to guidelines, ${ }^{24} 2528-3341425456-61$ of which 12 (50\%) significantly improved these measures (table 4). ${ }^{28} 303133414258-61$ Disease management for depression had the highest percentage of programmes with significant benefit (9/14). Overall, programmes with provider education components significantly improved provider adherence to guidelines (effect size 0.44 (0.19 to 0.68$)$ ).

Sixteen programmes with provider feedback evaluated provider adherence to guidelines (table 4). ${ }^{24} 2931-334246495458596263$ Nine of these (56\%) significantly improved provider adherence, ${ }^{31334246589}$ with programmes for depression being most successful $(8 / 12)$. Overall, these programmes were effective in improving provider adherence (effect size 0.61 ( 0.28 to 0.93)).

Ten programmes with provider reminders examined provider adherence (table 4). ${ }^{29-31} 54596364$ Six (60\%) significantly improved adherence, ${ }^{30} 315964$ with programmes for depression being most successful $(5 / 8)$. Overall, these programmes were also effective in improving provider adherence (effect size 0.52 ( 0.35 to $0.69))$.

\section{Impact of programmes with patient interventions on disease control}

Fifty five programmes included patient education and evaluated disease control (table 5). ${ }^{22-27}$ 29-31 3334363742 44-47 $495052535665-8891$ Of these, 24 (44\%) significantly improved disease control. ${ }^{24} 3031333436374244-475366676970$ $73747982-8488$ The highest percentage of programmes producing significant improvements were among those for depression (10/18), asthma (2/3), and hypertension (2/2). Overall, patient education produced a small but significant improvement in disease control (effect size 0.24 (0.07 to 0.40$)$ ).

Sixteen programmes including patient reminders evaluated disease control (table 5). ${ }^{22} 3443464749535468718182878990$ Six (38\%) significantly improved disease control. ${ }^{34} 4647538289$ The highest percentage of programmes producing significant improvements were among those for depression (2/3) and diabetes (4/7). Overall, programmes with patient reminders produced a small but significant improvement in disease control (effect size 0.27 (0.17 to 0.36$)$ ).

Four programmes incorporating patient financial incentives evaluated disease control (table 5). ${ }^{3328391}$ Three, including one depression programme ${ }^{33}$ and two hypertension programmes, ${ }^{83} 91$ significantly improved disease control. Overall, these programmes seemed effective in improving disease control (effect size 0.40 $(0.26$ to 0.54$))$.

\section{Discussion}

Our study showed that many different interventionsincluding provider education, provider feedback, provider reminders, patient education, patient reminders, and patient financial incentives-were associated with improvements in provider adherence to guidelines and patient disease control. However, since existing studies do not directly compare different interventions, less is known about which interventions produce the greatest relative improvements in care.

There should be careful consideration of the most effective strategies for changing provider and patient behaviour, since it is difficult to postulate any improvements in patient care if both provider and patient behaviour remains unchanged. Our study showed that many different types of intervention are being used in disease management programmes, with patient education being the commonest. Also, 59\% of disease management programmes used two or more interventions, possibly because multiple interventions are thought to be more likely to be successful than single interventions. The wide variety interventions used may reflect the paucity of available information to guide programme development and to define an optimal strategy. It is ironic that disease management

Table 5 Effects of disease management programmes with interventions directed at patients on disease control

\begin{tabular}{|c|c|c|c|c|c|c|}
\hline \multirow[b]{2}{*}{ Condition } & \multicolumn{2}{|c|}{ Programmes with patient education } & \multicolumn{2}{|c|}{ Programmes with patient reminders } & \multicolumn{2}{|c|}{$\begin{array}{l}\text { Programmes with patient financial } \\
\text { incentives }\end{array}$} \\
\hline & $\begin{array}{l}\text { No of effective } \\
\text { programmes* }\end{array}$ & $\begin{array}{l}\text { Pooled effect size }(95 \% \\
\text { CI) }\end{array}$ & $\begin{array}{l}\text { No of effective } \\
\text { programmes* }\end{array}$ & $\begin{array}{l}\text { Pooled effect size } \\
\quad(95 \% \mathrm{Cl})\end{array}$ & $\begin{array}{l}\text { No of effective } \\
\text { programmes* }\end{array}$ & $\begin{array}{l}\text { Pooled effect size } \\
(95 \% \mathrm{Cl})\end{array}$ \\
\hline Asthma & $2 / 3$ & $1.1(0.04$ to 2.1$)$ & $0 / 1$ & $0.03(-0.1$ to 0.19$)$ & & \\
\hline \multicolumn{7}{|l|}{ Back pain } \\
\hline Coronary artery disease & $1 / 3$ & 0.40 (0.18 to 0.62$)$ & $0 / 2$ & $0.31(-0.01$ to 0.63$)$ & & \\
\hline Chronic pain & $1 / 2$ & 0.87 (0.27 to 1.47$)$ & & & & \\
\hline \multicolumn{7}{|l|}{ Congestive heart failure } \\
\hline $\begin{array}{l}\text { Chronic obstructive } \\
\text { pulmonary disease }\end{array}$ & $0 / 2$ & $0.01(-0.38$ to 0.39$)$ & $0 / 1$ & $0.29(-0.3$ to 0.86$)$ & & \\
\hline Depression & $10 / 18$ & 0.27 (0.18 to 0.36$)$ & $2 / 3$ & $0.34(0.14$ to 0.55$)$ & $1 / 1$ & $0.26(0.1$ to 0.43$)$ \\
\hline Diabetes & $6 / 17$ & $0.22(0.15$ to 0.30$)$ & $4 / 7$ & $0.31(0.18$ to 0.44$)$ & & \\
\hline End stage renal disease & $0 / 1$ & $-0.25(-0.4$ to -0.06$)$ & & & & \\
\hline Hyperlipidaemia & $1 / 4$ & 0.20 (0.07 to 0.33$)$ & $0 / 1$ & $0.09(-0.27$ to 0.44$)$ & $0 / 1$ & $0.22(-0.04$ to 0.48$)$ \\
\hline Hypertension & $2 / 2$ & $1.6(0.30$ to 2.9$)$ & & & $2 / 2$ & 0.48 (0.44 to 0.53$)$ \\
\hline $\begin{array}{l}\text { Rheumatoid arthritis and } \\
\text { osteoarthritis }\end{array}$ & $1 / 3$ & $0.19(-0.11$ to 0.50$)$ & $0 / 1$ & $0.21(-0.31$ to 0.73$)$ & & \\
\hline All conditions & $24 / 55$ & $0.24(0.07$ to 0.40$)$ & $6 / 16$ & $0.27(0.17$ to 0.36$)$ & $3 / 4$ & $0.40(0.26$ to 0.54$)$ \\
\hline
\end{tabular}

${ }^{*}$ No of assessments showing significant treatment benefit $(\alpha=0.05) /$ total No of assessments. 
programmes are designed to reduce unexplained variations in care, yet there are large and unexplained variations in the design, development, and implementation of disease management programmes.

Because of the promise that disease management holds for improving patient care, about $\$ 1 \mathrm{bn}$ is invested in disease management programmes in the United States each year. ${ }^{4}$ The National Committee on Quality Assurance (NCQA) in the United States requires health plans to submit data on two disease management programmes each year for consideration of accreditation. However, this investment in disease management should be guided by information on how to optimise the benefits of these programmes. Unfortunately, disease management programme developers have had limited qualitative or quantitative information about which interventions achieve the greatest benefits, and programmes are therefore highly variable in design.

\section{Strengths and limitations of study}

To the best of our knowledge, our study is the first comprehensive attempt to evaluate the effectiveness of different disease management programmes for patients with chronic illness. Our study brought together disparate information of disease management, to allow for qualitative and quantitative interpretation. We evaluated 16917 different article titles and identified 102 different disease management studies. We evaluated multiple potential implementation strategies for many different diseases and conditions, and we evaluated both the process of care (provider adherence to guidelines) and the outcome of care (disease control). Disease control measures were carefully selected and related to the key clinical goals of the treatment of each disease. In addition, our study provided both qualitative and quantitative information to assess the effectiveness of different interventions; most other studies have evaluated only qualitative findings. ${ }^{4} 8$ 10-13 Therefore, in addition to integrated information on the effect sizes of interventions on patient disease control and adherence to guidelines, ${ }^{20}$ we have provided detailed descriptions of each study (see authors' website www.zynx.com\research\ disease_management.htm).

Our study has several limitations, most importantly the quality, quantity, and heterogeneity of the original studies. The studies included great variation in interventions used, patient populations, provider populations, and measured processes and outcomes of care. Many provided insufficient detail in the methods section for us to understand the quality of the interventions and the intensity or duration of each intervention. For example, a study might report that provider education was used, but provide insufficient information for readers to understand how the educational process was performed and how to replicate the process.

The clinical significance of effect sizes may be unclear and need to be interpreted with caution and related to the measured clinical effects reported in the trials. ${ }^{20}$ Few studies directly compared the effectiveness of different interventions, and without direct comparisons of interventions in trials it is difficult to evaluate each intervention's relative effectiveness.

\section{What is already known on this topic}

Disease management programmes have gained popularity in recent years as a means of improving the quality and efficiency of care of patients with chronic diseases

A limited number of trials have documented the effectiveness of disease management in specific situations, but uncertainty remains about its overall value and which interventions are most effective

\section{What this study adds}

Programmes using education, feedback, or reminders for healthcare providers produced significant improvements in provider adherence to care guidelines

Programmes using the provider strategies or education, reminders, or financial incentives for patients improved disease control

Further study is needed to assess the relative effectiveness of the different strategies

\section{Conclusions}

The available published literature shows that most disease management programmes directed at providers and patients are associated with improvements in care. However, little is known about the relative effectiveness and costs associated with different implementation strategies, and few studies have directly compared intervention strategies. Further research is needed to determine the effectiveness and costs of different implementation strategies that could be used in disease management programmes. These studies should adhere to methodological standards and be described in peer reviewed literature in sufficient detail to enable others to understand and reproduce the results in different patient populations, and to understand the relative effectiveness of different disease management interventions for improving the care of patients with chronic diseases.

We thank David Nash, David Shulkin, and Mark Zitter for providing extra references for our review.

Contributors: SRW, the principal investigator and guarantor for the study, initiated and designed the study, contributed to data analysis and interpretation, and oversaw the study. JMH advised on and helped with the study design, contributed to data interpretation, discussed core ideas, and obtained funding for the study. EB helped design data collection protocols, coordinated data collection, discussed core ideas, was data manager, analysed data, and contributed to data interpretation. KK contributed to the study methods, advised on research measures, discussed core ideas, commented on data analysis, and helped with data interpretation. $\mathrm{VH}$ guided and conducted the statistical analysis and commented on data analyses and interpretation. $\mathrm{AG} \mathrm{Jr}$ helped with data collection and management and data analyses and interpretation. JJO conceived the study and design, obtained funding, advised on and helped with study design, discussed core ideas, designed data collection protocols, and helped with data interpretation. SRW,JMH, KK, JJO, and EB jointly wrote, revised, and edited the paper.

Funding: This work was partially supported by a research grant from TAP Pharmaceutical Products.

Competing interests: SRW has been reimbursed for speaking at conferences on the topic of disease management and was a 
member of the NCQA Disease Management Advisory Committee. At the time of the study Zynx Health was owned by Cedars-Sinai Health System and affiliated with the UCLA School of Medicine; it is now a subsidiary of Cerner Corporation. At no time has it derived revenue from selling or providing services for disease management programmes.

1 Smith DH, Malone DC, Lawson KA, Okamoto LJ, Battista C, Saunder WB. A national estimate of the economic costs of asthma. Am J Respir Crit Care Med 1997;156:787-93.

2 Greenberg PE, Stiglin LE, Finkelstein SN, Berndt ER. The economi burden of depression in 1990. J Clin Psychiatry 1993;54:405-18.

3 American Diabetes Association. Economic consequences of diabete mellitus in the US in 1997. Diabetes Care 1998;21:296-309.

4 Ellrodt G, Cook DJ, Lee J, Cho M, Hunt D, Weingarten S. Evidence-based disease management. JAMA 1997;278:1687-92.

5 Epstein WA, Sanchez M, Kechijian P. Conjunctivitis. Arch Dermatol 1985;121:838

6 Wehrwein P. What happens when politicians play doctor. Manag Car 1997;6:28-34.

7 Oxman AD, Thomson MA, Davis DA, Haynes RB. No magic bullets: a systematic review of 102 trials of interventions to improve professional practice. CMAJ 1995; 153:1423-31.

8 Davis DA, Thomson MA, Oxman AD, Haynes RB. Evidence for the effectiveness of CME. A review of 50 randomized controlled trials. JAMA 1992:268:1111-7.

9 Mugford M, Banfield P, O'Hanlon M. Effects of feedback of information on clinical practice: a review. BMJ 1991;303:398-402

10 Grol R. Beliefs and evidence in changing clinical practice. $B M J$ 1997;315:418-21

11 Davis DA, Taylor-Vaisey A. Translating guidelines into practice. A systematic review of theoretic concepts, practical experience and research evidence in the adoption of clinical practice guidelines. CMAJ 1997;157:408-16

2 Grimshaw JM, Russell IT. Effect of clinical guidelines on medical practice: a systematic review of rigorous evaluations. Lancet 1993;342:1317-22.

13 Committee to Advise the Public Health Service on Clinical Practice Guidelines, Institute of Medicine. Clinical practice guidelines: directions for a new program. Washington DC: National Academy Press, 1990.

14 Cochrane Effective Practice and Organisation of Care Group (EPOC) information page. Cochrane Database of Systematic Reviews website http://gateway.ovid.com/rel410/server1/ovidweb.cgi (accessed $19 \mathrm{Ju}$ 2000).

15 Rosenthal R, Rubin D. Combining results from independent studies. Psychol Bull 1979;85:185-93.

16 Glass G. Summarizing effect sizes. New directions for methodology of social and behavioral science: quantitative assessment of research domains. San Francisco CA: Jossey-Bass, 1980

17 Rosenthal R. Meta-analytic procedures for social research. Beverly Hills CA Sage Publications, 1984

8 Hedges LV, Olkin I. Statistical methods for meta-analysis. Orlando FL: Academic Press, 1985

19 Hasselblad V, Hedges LV. Meta-analysis of screening and diagnostic tests. Psychol Bull 1995;117:167-78.

20 Kazis LE, Anderson JJ, Meenan RF. Effect size for interpreting changes in health status. Med Care 1989;27:S178-89.

21 DerSimonian R, Laird N. Meta-analysis in clinical trials. Control Clin Trials 1986;7:177-88

22 DeBusk RF, Miller NH, Superko HR, Dennis CA, Thomas RJ, Lew HT, et al. A case-management system for coronary risk factor modification after acute myocardial infarction. Ann Intern Med 1994;120:721-9.

23 Hunkeler EM, Meresman JF, Hargreaves WA, Fireman B, Berman WH, Kirsch AJ, et al. Efficacy of nurse telehealth care and peer support in augmenting treatment of depression in primary care. Arch Fam Med 2000;9:700-8.

24 Katon W, Rutter C, Ludman EJ, Von K, Lin E, Simon G, et al. A randomized trial of relapse prevention of depression in primary care. Arch Gen Psychiatry 2001;58:241-7.

25 Lin EH, Simon GE, Katon WJ, Russo JE, Von K, Bush TM, et al. Can enhanced acute-phase treatment of depression improve long-term outcomes? A report of randomized trials in primary care. Am J Psychiatr 1999;156:643-5.

26 Llewellyn-Jones RH, Baikie KA, Smithers H, Cohen J, Snowdon J, Tennant CC. Multifaceted shared care intervention for late life depression in residential care: randomised controlled trial. $B M J$ 1999;319:676-82.

27 Whooley MA, Stone B, Soghikian K. Randomized trial of case-finding for depression in elderly primary care patients. J Gen Intern Med 2000;15:293-300

28 Worrall G, Angel J, Chaulk P, Clarke C, Robbins M. Effectiveness of an educational strategy to improve family physicians' detection and management of depression: a randomized controlled trial. CMA 1999;161:37-40.

29 Callahan CM, Hendrie HC, Dittus RS, Brater DC, Hui SL, Tierney WM. Improving treatment of late life depression in primary care: a randomized clinical trial. JAm Geriatr Soc 1994;42:839-46.

30 Katon W, Robinson P, Von KM, Lin E, Bush T, Ludman E, et al. A multifaceted intervention to improve treatment of depression in primary care. Arch Gen Psychiatry 1996;53:924-32.

31 Katon W, Von Korff M, Lin E, Walker E, Simon GE, Bush T, et al. Collaborative management to achieve treatment guidelines. Impact on depression in primary care. JAMA 1995;273:1026-31

32 Thompson C, Kinmonth AL, Stevens L, Peveler RC, Stevens A, Ostler KJ et al. Effects of a clinical-practice guideline and practice-based education on detection and outcome of depression in primary care: Hampshire depression project randomised controlled trial. Lancet 2000;355:185-91. 33 Wells KB, Sherbourne C, Schoenbaum M, Duan N, Meredith L, Unutze $\mathrm{J}$, et al. Impact of disseminating quality improvement programs for depression in managed primary care: a randomized controlled trial. JAMA 2000;283:212-20.

34 Aubert RE, Herman WH, Waters J, Moore W, Sutton D, Peterson BL, et al. Nurse case management to improve glycemic control in diabetic patient in a health maintenance organization. A randomized, controlled trial. Ann Intern Med 1998;129:605-12.

35 Benjamin EM, Schneider MS, Hinchey KT. Implementing practice guidelines for diabetes care using problem-based learning. A prospective controlled trial using firm systems. Diabetes Care 1999;22:1672-8.

36 Vinicor F, Cohen SJ, Mazzuca SA, Moorman N, Wheeler M, Kuebler T, et al. DIABEDS: a randomized trial of the effects of physician and/or patien education on diabetes patient outcomes. J Chronic Dis 1987;40:345-56.

37 Erickson SR, Slaughter R, Halapy H. Pharmacists' ability to influence outcomes of hypertension therapy. Pharmacotherapy 1997;17:140-7.

38 Gourley GA, Portner TS, Gourley DR, Rigolosi EL, Holt JM, Solomon DK, et al. Humanistic outcomes in the hypertension and COPD arms of a multicenter outcomes study. J Am Pharm Assoc 1998;38:586-97.

39 Bogden PE, Koontz LM, Williamson P, Abbott RD. The physician and pharmacist team. An effective approach to cholesterol reduction. J Gen Intern Med 1997;12:158-64.

40 Katz S, Vignos PJ Jr, Moskowitz RW, Thompson HM, Svec KH. Comprehensive outpatient care in rheumatoid arthritis. A controlled study. JAMA 1968;206:1249-54

41 Rost K, Nutting P, Smith J, Werner J, Duan N. Improving depression outcomes in community primary care practice: a randomized trial of the quEST intervention. Quality enhancement by strategic teaming. J Gen Intern Med 2001:16:143-9.

42 Katzelnick DJ, Simon GE, Pearson SD, Manning WG, Helstad CP, Henk $\mathrm{HJ}$, et al. Randomized trial of a depression management program in high utilizers of medical care. Arch Fam Med 2000;9:345-51.

43 Integrated care for asthma: a clinical, social, and economic evaluation. Grampian asthma study of integrated care (GRASSIC). BMJ 1994:308:559-64

44 Simon GE, VonKorff M, Rutter C, Wagner E. Randomised trial of monitoring, feedback, and management of care by telephone to improve treatment of depression in primary care. BMJ 2000;320:550-4

45 Tutty S, Simon G, Ludman E. Telephone counseling as an adjunct to antidepressant treatment in the primary care system. A pilot study. Eff Clin Pract 2000;3:170-8.

46 Walker EA, Katon WJ, Russo J, Von K, Lin E, Simon G, et al. Predictors of outcome in a primary care depression trial. J Gen Intern Med 2000;15:859-67.

47 Katon W, Von K, Lin E, Simon G, Walker E, Unutzer J, et al. Stepped collaborative care for primary care patients with persistent symptoms of depression: a randomized trial. Arch Gen Psychiatry 1999;56:1109-15

48 Kulkarni K, Castle G, Gregory R, Holmes A, Leontos C, Powers M, et al. Nutrition practice guidelines for type 1 diabetes mellitus positively affect dietitian practices and patient outcomes. The Diabetes Care and Education Dietetic Practice Group. J Am Diet Assoc 1998;98: 62-70, quiz 71-2.

49 Piette JD, Weinberger M, Kraemer FB, McPhee SJ. Impact of automated calls with nurse follow-up on diabetes treatment outcomes in a department of Veterans Affairs health care system: a randomized controlled trial. Diabetes Care 2001:24:202-8.

50 Harris LE, Luft FC, Rudy DW, Kesterson JG, Tierney WM. Effects of multidisciplinary case management in patients with chronic renal insufficiency. Am J Med 1998;105:464-71

51 Hetlevik I, Holmen J, Kruger O. Implementing clinical guidelines in the treatment of hypertension in general practice. Evaluation of patient outcome related to implementation of a computer-based clinical decision support system. Scand J Prim Health Care 1999;17:35-40.

52 Fielding JE, Mason T, Kinght K, Klesges R, Pelletier KR. A randomized trial of the IMPACT worksite cholesterol reduction program. Am J Preu Med 1995;11:120-3

53 De Sonnaville J, Bouma M, Colly LP, Deville W, Wijkel D, Heine RJ. Sustained good glycaemic control in NIDDM patients by implementation of structured care in general practice: 2-year follow-up study. Diabetologia 1997;40:1334-40.

54 Hurwitz B, Goodman C, Yudkin J. Prompting the clinical care of non-insulin dependent (type II) diabetic patients in an inner city area: one model of community care. BMJ 1993;306:624-30

55 Bogden PE, Abbott RD, Williamson P, Onopa JK, Koontz LM. Comparing standard care with a physician and pharmacist team approach for uncontrolled hypertension. J Gen Intern Med 1998;13:740-5 56 Kinmonth AL, Woodcock A, Griffin S, Spiegal N, Campbell M] Randomised controlled trial of patient centred care of diabetes in general practice: impact on current wellbeing and future disease risk. The Diabetes Care From Diagnosis Research Team. BMJ 1998;317:1202-8.

57 Montgomery AA, Fahey T, Peters TJ, MacIntosh C, Sharp DJ. Evaluation of computer based clinical decision support system and risk chart for management of hypertension in primary care: randomised controlled trial. $B M J$ 2000;320:686-90.

58 Heller RF, D'Este C, Lim LL, O'Connell RL, Powell H. Randomised controlled trial to change the hospital management of unstable angina. Med J Aust 1988;174:217-21.

59 Smith JL, Rost KM, Nutting PA, Elliott CE, Duan N. A primary care intervention for depression.J Rural Health 2000;16:313-23.

60 Donohoe ME, Fletton JA, Hook A, Powell R, Robinson I, Stead JW, et al Improving foot care for people with diabetes mellitus-a randomized controlled trial of an integrated care approach. Diabet Med 2000;17:581-7. 
61 Browner WS, Baron RB, Solkowitz S, Adler LJ, Gullion DS. Physician management of hypercholesterolemia. A randomized trial of continuing medical education. West J Med 1994;161:572-8.

62 Gattis WA, Hasselblad V, Whellan DJ, O'Connor CM. Reduction in heart failure events by the addition of a clinical pharmacist to the heart failure management team: results of the pharmacist in heart failure assessment recommendation and monitoring (PHARM) study. Arch Intern Med 1999:159:1939-45

63 Magruder-Habib K, Zung WW, Feussner JR. Improving physicians' recognition and treatment of depression in general medical care. Results from a randomized clinical trial. Intervention for minor depression in primary care patients. Med Care 1990;28:239-50.

64 Litzelman DK, Slemenda CW, Langefeld CD, Hays LM, Welch MA, Bild $\mathrm{DE}$, et al. Reduction of lower extremity clinical abnormalities in patients with non-insulin-dependent diabetes mellitus. A randomized, controlled trial. Ann Intern Med 1993;119:36-41.

65 Mulloy E, Donaghy D, Quigley C, McNicholas WT. A one-year prospective audit of an asthma education program in an out-patient setting. Ir Med J 1996;89:226-8.

66 Ignacio-Garcia JM, Gonzalez-Santos P. Asthma self-management education program by home monitoring of peak expiratory flow. Am J Respir Crit Care Med 1995:151:353-9.

67 Sont JK, Willems LN, Bel EH, van Krieken J, Vandenbroucke JP, Sterk PJ. Clinical control and histopathologic outcome of asthma when using airway hyperresponsiveness as an additional guide to long-term treatment. The AMPUL Study Group. Am J Respir Crit Care Med 1999;159:1043-51.

68 Lidell E, Fridlund B. Long-term effects of a comprehensive rehabilitation program after myocardial infarction. Scand J Caring Sci 1996;10:67-74.

69 Hedback B, Perk J, Wodlin P. Long-term reduction of cardiac mortality after myocardial infarction: 10-year results of a comprehensive rehabilitation program. Eur Heart J 1993; 14:831-5.

70 Peters JL, Large RG. A randomised control trial evaluating in- and outpatient pain management programs. Pain 1990;41:283-93.

71 Ries AL, Kaplan RM, Limberg TM, Prewitt LM. Effects of pulmonary rehabilitation on physiologic and psychosocial outcomes in patients with chronic obstructive pulmonary disease. Ann Intern Med 1995;122:823-32.

72 Troosters T, Gosselink R, Decramer M. Short- and long-term effects of outpatient rehabilitation in patients with chronic obstructive pulmonary disease: a randomized trial. Am J Med 2000;109:207-12

73 Banerjee S, Shamash K, Macdonald AJ, Mann AH. Randomised controlled trial of effect of intervention by psychogeriatric team on depression in frail elderly people at home. BMJ 1996;313:1058-61.

74 D'Eramo-Melkus GA, Wylie-Rosett J, Hagan JA. Metabolic impact of education in NIDDM. Diabetes Care 1992;15:864-9.

75 Diabetes Integrated Care Evaluation Team. Integrated care for diabetes: clinical, psychosocial, and economic evaluation. BMJ 1994:308:1208-12.

76 De Weerdt I, Visser AP, Kok GJ, de Weerdt O, van der Veen EA. Randomized controlled multicentre evaluation of an education program for insulin-treated diabetic patients: effects on metabolic control, quality of life, and costs of therapy. Diabet Med 1991;8:338-45.

77 Domenech MI, Assad D, Mazzei ME, Kronsbein P, Gagliardino IJ. Evaluation of the effectiveness of an ambulatory teaching/treatment program for non-insulin dependent (type 2) diabetic patients. Acta Diabetol 1995;32:143-7.
78 Franz MJ, Monk A, Barry B, McClain K, Weaver T, Cooper N, et al. Effectiveness of medical nutrition therapy provided by dietitians in the management of non-insulin-dependent diabetes mellitus: a randomized, controlled clinical trial. J Am Diet Assoc 1995;95:1009-17.

79 Jaber LA, Halapy H, Fernet M, Tummalapalli S, Diwakaran H. Evaluation of a pharmaceutical care model on diabetes management. Ann Pharmacother 1996;30:238-43.

80 Mazzuca SA, Moorman NH, Wheeler ML, Norton JA, Fineberg NS, Vinicor F, et al. The diabetes education study: a controlled trial of the effects of diabetes patient education. Diabetes Care 1986;9:1-10.

81 Ridgeway NA, Harvill DR, Harvill LM, Falin TM, Forester GM, Gose OD. Improved control of type 2 diabetes mellitus: a practical education behavior modification program in a primary care clinic. South Med J 1999;92:667-72.

82 Weinberger M, Kirkman MS, Samsa GP, Shortliffe EA, Landsman PB, Cowper PA, et al. A nurse-coordinated intervention for primary care patients with non-insulin-dependent diabetes mellitus: impact on glycemic control and health-related quality of life. J Gen Intern Med 1995; 10:59-66.

83 Fielding JE, Knight K, Mason T, Klesges RC, Pelletier KR. Evaluation of the IMPACT blood pressure program. J Occup Med 1994;36:743-6.

84 Ellis SL, Carter BL, Malone DC, Billups SJ, Okano GJ, Valuck RJ, et al. Clinical and economic impact of ambulatory care clinical pharmacists in management of dyslipidemia in older adults: the IMPROVE study. impact of managed pharmaceutical care on resource utilization and outcomes in Veterans Affairs medical centers. Pharmacotherapy 2000;20:1508-16.

85 Keyserling TC, Ammerman AS, Davis CE, Mok MC, Garrett J, Simpson RJ. A randomized controlled trial of a physician-directed treatment program for low-income patients with high blood cholesterol: the southeast cholesterol project. Arch Fam Med 1997;6:135-45.

86 Bell MJ, Lineker SC, Wilkins AL, Goldsmith CH, Badley EM. A randomized controlled trial to evaluate the efficacy of community based physical therapy in the treatment of people with rheumatoid arthritis. $J$ Rheumatol 1998;25:231-7.

87 Schned ES, Doyle MA, Glickstein SL, Schousboe JT, Reinertsen JL, Baglioni AJ, et al. Team managed outpatient care for early onset chronic inflammatory arthritis. J Rheumatol 1995;22:1141-8.

88 Vliet Vlieland TP, Zwinderman AH, Vandenbroucke JP, Breedveld FC, Hazes JM. A randomized clinical trial of in-patient multidisciplinary treatment versus routine out-patient care in active rheumatoid arthritis. Br J Rheumatol 1996;35:475-82.

89 O'Connor PJ, Rush WA, Peterson J, Morben P, Cherney L, Keogh C, et al Continuous quality improvement can improve glycemic control for HMO patients with diabetes. Arch Fam Med 1996;5:502-6.

90 Hyman DJ, Ho KS, Dunn JK, Simons-Morton D. Dietary intervention for cholesterol reduction in public clinic patients. Am J Prev Med $1998 ; 15: 139-45$

91 Hypertension Detection and Follow-up Program Cooperative Group. Five-year findings of the hypertension detection and follow-up program. II. Mortality by race-sex and age. JAMA 1979;242:2572-7.

(Accepted 6 September 2002) 